\title{
Role of Nurse in Nutritional Care
}

\author{
Bushra Mushtaq* \\ Psychiatry Nursing Scholar, India \\ *Corresponding author: Mushtaq B, PG Psychiatry Nursing Scholar, Srinagar, India
}

Submission: May 11, 2018; Published: May 15, 2018

\section{Opinion}

Nutrition is very essential for normal body functioning. Nutrition for the clients with disease helps in the prompt healing and early recovery. Nurse has role to play in both hospital and community settings and nurse plays a dramatic role in different levels of health care. Broadly categorizing nurse has different roles at different levels.

\section{Health Education}

Health education being an extremely powerful component in achieving the adequate healthy life, nurse uses health education component as a tool in every setting and where ever needed like hospitals, clinics, community, schools, etc.

1. Nurse educates about healthy and balanced diet to the peoples.

2. Gives knowledge about recommendations required by different age and gender groups.

3. Educated about best and easy ways to achieve good nutritious diet.

4. Managing easy nutrients from locally available foods.

5. Education about the Menu planning.

\section{Hospitals}

Nurse working in different wards of hospital are very vigilant in maintaining adequate nutrition levels for the client admitted.

1. In hospital nurse has to take care of nutritional aspects of the admitted client in ward.

2. Educates the client as well as family members regarding the importance of the healthy and nutritious diet.
3. Nurse maintains the adequate diet plans for the client.

4. Helps in monitoring the conditions of the client like vomiting, input-output, electrolyte monitoring, in order to add different components in the diet.

5. Maintaining parental nutrition for the client.

6. Maintenance of adequate hydration.

\section{Community}

In community nurse focuses on the prevention aspect i.e. helps in giving the basic education regarding prevention of certain nutritional deficiency disease. At the community level the nurse can act as:

1. Community health nurse.

2. School health nurse.

And work in different sectors where she mainly works at grass root levels to correct the nutritional deficiencies in the client.

1. Nurse rectifies the different patterns of the nutrition opted by the people.

2. Nurse collaborates with government and non-govt. agencies working for nutritional betterment of public sectors.

3. Nurse plays a role in school health programs as school health nurse, helps in identification of malnourished children and maintains growth charts.

4. Involvement of family. 
Creative Commons Attribution 4.0 International License

For possible submissions Click Here
Novel Techniques in Nutrition and Food Science

Benefits of Publishing with us

- High-level peer review and editorial services

- Freely accessible online immediately upon publication

- Authors retain the copyright to their work

- Licensing it under a Creative Commons license

- Visibility through different online platforms 